Original Research Article

\title{
A world health organization core drug use indicator based prescription study in the dermatology outpatient department of a tertiary care teaching hospital of central South India
}

\author{
Mahendra K. Jaiswal $^{1}$, Rajnesh K. Chakrawarty ${ }^{2 *}$, Sanat K. Sharma ${ }^{1}$, Raj K. Sharma ${ }^{1}$, \\ Rupendra K. Bharti ${ }^{1}$, Ratna Agrawal ${ }^{1}$
}

${ }^{1}$ Department of Pharmacology, Late BRKM Government Medical College, Jagdalpur, Chhattisgarh, India ${ }^{2}$ Department of Skin and V.D., Late BRKM Government Medical College, Jagdalpur, Chhattisgarh, India

Received: 08 June 2019

Revised: 29 June 2019

Accepted: 03 July 2019

*Correspondence to:

Dr. Rajnesh K. Chakrawarty, Email: chakrwartyrajnesh8@ gmail.com

Copyright: (C) the author(s), publisher and licensee Medip Academy. This is an openaccess article distributed under the terms of the Creative Commons Attribution NonCommercial License, which permits unrestricted noncommercial use, distribution, and reproduction in any medium, provided the original work is properly cited.

\begin{abstract}
Background: Irrational prescribing is a universal problem that may lead to inadequate response to medication therapy, poor patient compliance and increased adverse drug reactions ultimately leading to frequent hospital admissions. Hence this study was done to assess the drug utilization pattern using WHO core drug use indicators so that the recommendation can be made towards the rational prescribing.

Methods: A sample of 3650 prescriptions was analysed prospectively to assess the drug utilization patterns in the dermatology OPD of a tertiary care teaching hospital of central south India.

Results: The average number of drugs per prescription was 2.74 whereas $79.26 \%$ drugs were prescribed by generic names. Percentage of encounters with an antibiotic prescribed was $18.68 \%$. Regarding use of injections, $3.26 \%$ prescriptions contains one or more injections. Percentage of drugs prescribed from essential drugs list was $78.37 \%$. Average consultation time was lower (2.9 minutes) than recommended.

Conclusions: The data from the present study indicates that prevalence of polypharmacy, inadequate consultation and dispensing time along with poor patient's knowledge are the areas of medication therapy to be improved. Availability of essential drugs and key drugs in stock should be improved to achieve rational therapeutic goal. Further, continued medical education regarding the rational prescribing will definitely improve the standards of health care delivery.
\end{abstract}

Keywords: Dermatology, Essential drug list, Polypharmacy, Prescription analysis, WHO core drug use indicators.

\section{INTRODUCTION}

Prescription is an instruction written by a medical practitioner that authorizes a patient to be issued with a medicine or treatment. ${ }^{1}$ A prescription is handwritten on pre-printed prescription forms or printed onto a computer printer or sometimes entered into an electronic medical record system and transmitted electronically to a pharmacy in advanced setup.
Prescriptions are also used to differentiate prescription drugs from drugs that are not strictly regulated as a prescription drug. Prescriptions, when handwritten, are notorious for being often illegible.

In the US, illegible handwriting is at least indirectly responsible for the deaths of 7,000 people annually, according to a July 2006 report from the National Academies of Science's Institute of Medicine (IOM). ${ }^{2}$ 
All written prescriptions should contain Patient's full name and address; Prescriber's full name, address, telephone number and registration number; Date of issuance; Signature of prescriber; Drug name, dose, dosage form, amount; Directions for use and Refill instructions. ${ }^{3}$ Medication errors are common in general practice and in hospitals. Both errors in the act of writing (prescription errors) and prescribing faults due to erroneous medical decisions can result in harm to patients and although they are rarely fatal, they can affect patients' safety and quality of healthcare. ${ }^{4}$ Studies carried out in US hospitals suggest that prescribing errors occur in $0.4-1.9 \%$ of all medication orders written ${ }^{5-7}$ and cause harm in about $1 \%$ of all inpatients. $^{8}$

A medication error is a preventable event that could result in inappropriate therapy or harm to a patient. ${ }^{9}$ Periodic prescription analysis known as prescription audit is a way to control irrational prescribing. It minimizes overuse and misuse of drugs, enhance the therapeutic efficacy, minimize the adverse effect, plan essential drug selection, optimize the cost of the therapy, provide useful feedback to the clinician and estimate the drug need of the community, thus have a favourable impact on the standards of treatment. ${ }^{10}$

The aim of this study is to analyse various aspects of prescription pattern and rational use of drugs by dermatologists to generate the base line data and thus to help the dermatology prescriber to achieve rational and affordable therapy to their patients.

\section{METHODS}

This prospective observational study was carried out in Late B.R.K.M. Govt. Medical College, a tertiary care teaching hospital situated at Jagdalpur city of Bastar district, a tribal region of Chhattisgarh state of India, for duration of three months from January 2015 to March 2015 after taking permission from the institutional ethics committee. All the prescriptions issued to the patients attending the dermatology outpatient department following the consultation were entered in the case record forms as per WHO guidelines (1993) for Drug Utilization Studies. The data collected included demographic data, symptoms, diagnosis, number and class of drugs, name of drug with the dose, duration, strength, quantity to be applied, frequency of administration and fixed dose combinations. The Prescriptions were subjected to critical evaluation using WHO core drug use indicators. ${ }^{11}$ All the findings were recorded, compiled, tabulated and analysed. The data was analysed by simple proportion.

\section{RESULTS}

\section{Patient demographics}

This study included 3650 prescriptions collected from various age groups comprising of around $51.48 \%$ male and $48.52 \%$ female patients. The patient's name, age and sex were mentioned on $100 \%$ of the prescriptions. A maximum of around $32.63 \%$ prescriptions were collected from age group of 21-30 year followed by $23.64 \%$ from the age group of 11-20 year (Table 1).

\section{Table 1: Socio-demographic characteristics of patients.}

\begin{tabular}{|llll|}
\hline Parameter & Characteristics & $\begin{array}{l}\text { Frequency } \\
(\mathbf{n = 3 6 5 0 )}\end{array}$ & Percentage \\
\hline \multirow{3}{*}{ Gender } & Male & 1879 & 51.48 \\
\cline { 2 - 4 } & Female & 1771 & 48.52 \\
\hline \multirow{4}{*}{ Age } & $0-10$ & 395 & 10.82 \\
\cline { 2 - 4 } & $11-20$ & 863 & 23.64 \\
\cline { 2 - 4 } & $21-30$ & 1191 & 32.63 \\
\cline { 2 - 4 } & $31-40$ & 539 & 14.77 \\
\hline & $41-50$ & 331 & 9.07 \\
\hline & $51-60$ & 186 & 5.10 \\
\hline
\end{tabular}

\section{Disease distribution}

A total of 124 different dermatological disorders were observed in the current study during analysis of 3650 prescriptions. Most common cases reported were scabies (9.51\%), Acne Vulgaris (8.16\%) and Allergic Contact Dermatitis $(5.42 \%)$. Diagnosis was written in $89.31 \%$ of the prescriptions (Table 2).

Table 2: Distribution of common skin conditions as per diagnosis

\begin{tabular}{|lll|}
\hline Diseases/Conditions & Total cases $(\mathbf{n = 3 6 5 0})$ & $\%$ \\
\hline Scabies & 347 & 9.51 \\
\hline Acne Vulgaris & 298 & 8.16 \\
\hline $\begin{array}{l}\text { Allergic Contact } \\
\text { Dermatitis }\end{array}$ & 198 & 5.42 \\
\hline Tinea Corporis & 157 & 4.30 \\
\hline Furuncle/Carbuncle & 153 & 4.19 \\
\hline Melasma & 138 & 3.78 \\
\hline Urticaria & 121 & 3.32 \\
\hline Tinea Cruris & 93 & 2.55 \\
\hline $\begin{array}{l}\text { Post Inflammatory } \\
\text { Hyperpigmentation }\end{array}$ & 85 & 2.33 \\
\hline Pityriasis alba & 82 & 2.25 \\
\hline $\begin{array}{l}\text { Rest } \\
\text { diseases/conditions }\end{array}$ & 1978 & 54.19 \\
\hline
\end{tabular}

\section{WHO core drug use indicators analysis}

The total number of drugs prescribed in the 3650 prescriptions was 10002 . Of the 10002 drugs, the most commonly prescribed class of drugs was Antiallergics (23.35\%) followed by Antacids (17.52\%) and Antibiotics (13.02\% of total drugs prescribed) (Table 3). On analysing the data as per total number of drugs used, out of total 2336 prescribed antihistaminic, $96.96 \%$ were prescribed by oral route and remaining $3.04 \%$ by injectable route. Majority 
of the Corticosteroid were given by the topical route $(730$ out of 1030, $70.87 \%$ ) while few Corticosteroids (25.14\%) were given by oral route. Injectable Corticosteroids were prescribed only in $3.98 \%$ of total Corticosteroid use.

Table 3: Main therapeutic categories of drugs.

\begin{tabular}{|llllll|}
\hline \multirow{2}{*}{ Category } & \multicolumn{2}{l}{ Route of Administration of each drug } & Total Number of Drugs (n=10002) & Percentage \\
\hline Analgesics & Oral & Topical & Injections & & 3.43 \\
\hline Antacids & 267 & 47 & 29 & 343 & 17.52 \\
\hline Antihistaminics & 1752 & 0 & 0 & 1752 & 23.35 \\
\hline Antibiotics & 2265 & 0 & 71 & 2336 & 13.02 \\
\hline Antiemetics & 566 & 427 & 9 & 1302 & 0.71 \\
\hline Antifungals & 396 & 0 & 18 & 71 & 14.68 \\
\hline Corticosteroids & 259 & 730 & 41 & 1468 & 10.30 \\
\hline Scabicides & 250 & 671 & 0 & 1030 & 9.21 \\
\hline Miscellaneous & 460 & 310 & 9 & 921 & 7.79 \\
\hline Total & 6568 & 3183 & 251 & 10002 & 100 \\
\hline
\end{tabular}

Most preferred route for administration of Antibiotics was oral (866 out of $1302,66.51 \%)$. Majority of the Antibiotics were given by the combination therapy of oral and topical route $(1036$ out of $1302,79.57 \%)$ while very few Antibiotics $(0.15 \%)$ were given by topical only route. Injectable Antibiotics were prescribed only in $0.69 \%$ of total Antibiotics use. Out of total 1468 prescribed antifungals, $67.98 \%$ were prescribed by topical route, $26.97 \%$ by oral route and $5.05 \%$ by injectable route. Antacids, Analgesics, Antiemetics and Miscellaneous drugs comprised about 2945 drugs and majority (85.98\%) of them was prescribed for oral route, $12.12 \%$ topically and $1.9 \%$ by injections. Scabicides were mainly prescribed topically $(72.85 \%)$ and orally $(27.15 \%)$.

Out of all the drugs prescribed, $31.82 \%$ were advised to be administere by the topical route, $65.67 \%$ by the oral route and $2.51 \%$ by injectable route. Fixed dose combinations were given in $1.38 \%$ cases. Total $8 \%$ of the prescriptions carried instructions or special instructions to patient, rest all patients were given verbal instructions.

Table 4: Incidence of polypharmacy in studied dermatology unit.

\begin{tabular}{|lll|}
\hline $\begin{array}{l}\text { Number of } \\
\text { drugs/prescriptions }\end{array}$ & $\begin{array}{l}\text { Number of } \\
\text { prescriptions } \\
(\mathbf{n = 3 6 5 0 )}\end{array}$ & $\%$ \\
\hline 0 & 151 & 4.14 \\
\hline 1 & 55 & 1.51 \\
\hline 2 & 835 & 22.88 \\
\hline 3 & 2136 & 58.52 \\
\hline 4 & 434 & 11.89 \\
\hline 5 & 15 & 0.41 \\
\hline 6 & 14 & 0.38 \\
\hline 7 & 10 & 0.27 \\
\hline
\end{tabular}

\section{A. Prescribing indicators}

\section{Average number of drugs per encounter}

The maximum number of drugs on a single prescription was seven and the minimum was one. No drugs prescribed in $4.14 \%$ cases and were treated by Laser, minor surgical procedure or reassurance. For 473 patients $(12.96 \%), \geq 4$ drugs were prescribed on a single prescription. The average number of drugs per prescription was 2.74 (Table 4).

\section{Percentage of drugs prescribed by generic name}

Most of the drugs $(79.26 \%)$ were prescribed by generic names. Other prescribing data were specified in majority of prescriptions in this study (Dose/strength in $88.16 \%$, frequency in $98 \%$ and duration of treatment in $81.21 \%$ of total prescriptions) (Table 5).

Table 5: Details of other information of prescriptions.

\begin{tabular}{|lll|}
\hline Parameters & $\begin{array}{l}\text { Specified in } \\
\text { Frequency } \\
(\mathbf{n = 3 6 5 0 )}\end{array}$ & Percentage \\
\hline Generic names & 2893 & 79.26 \\
\hline Dose/Strength & 3218 & 88.16 \\
\hline $\begin{array}{l}\text { Frequency of } \\
\text { administration }\end{array}$ & 3577 & 98.00 \\
\hline Duration of treatment & 2964 & 81.21 \\
\hline
\end{tabular}

\section{Percentage of encounters with an antibiotic prescribed}

Antibiotics were prescribed in 682 prescriptions (18.68\% of total prescriptions). The total number of Antibiotics prescribed in the 3650 prescriptions was 1302 (13.02\% of total drugs prescribed). Antibiotics are most commonly 
prescribed for Acne vulgaris (298 patients, $8.16 \%$ of total prescriptions) followed by Furuncle/Carbuncle (153 patients, $4.19 \%$ of total prescriptions) and Hansen's disease (50 patients, $1.37 \%$ of total prescriptions) (Table $6)$.

Table 6: Common indications for Antibiotics in current study.

\begin{tabular}{|lll|}
\hline Diagnosis & No. of prescriptions & Percentage of total prescription $(\mathbf{n = 3 6 5 0 )}$ \\
\hline Acne vulgaris & 298 & 8.16 \\
\hline Furuncle/Carbuncle & 153 & 4.19 \\
\hline Hansen's disease (Leprosy) & 50 & 1.37 \\
\hline Impetigo & 41 & 1.12 \\
\hline Infective eczematous dermatitis (IED) & 36 & 0.99 \\
\hline Genital ulcer & 16 & 0.44 \\
\hline Trophic ulcer & 14 & 0.38 \\
\hline Acneiform eruption & 12 & 0.33 \\
\hline Recurrent furunculosis & 11 & 0.30 \\
\hline Syphilis & 10 & 0.27 \\
\hline Others & 41 & 1.12 \\
\hline Total & 682 & 18.68 \\
\hline
\end{tabular}

\section{Percentage of encounters with an injection prescribed}

Injections were used in limited number of prescriptions and usually given in cases of systemic fungal infections, severe infections not responding to oral antibiotics and as intralesional corticosteroids. Out of the 3650 prescriptions analysed, $119(3.26 \%)$ prescriptions contains one or more injections.

\section{Percentage of drugs prescribed from essential drugs list or formulary}

Result was calculated by dividing the total number of drugs prescribed (7839) from the C.G. Essential Drug List ${ }^{12}$ by the total number of drugs prescribed (10002) and multiplied by 100 to make a percentage. Percentage of drugs prescribed from essential drugs list was $78.37 \%$.

\section{B. Patient care indicators}

The average consultation time was 2.9 minutes. The average dispensing time was 58 seconds. $84.63 \%$ of the prescribed drugs were actually dispensed. All dispensed drugs were adequately labelled. The percentage of patient's knowledge of the correct dosage was $37 \%$.

\section{Facility indicators}

The percentage availability of the EDL copy was $100 \%$ and of key drugs in the stock was $61.86 \%$.

\section{DISCUSSION}

Analysis of the patient data revealed that majority of patients are of age group of 21-30 years, followed by 1120 years. Gender-wise distribution shows that proportion of male patients $(51.48 \%)$ was more than female patients $48.52 \%$. This is similar to studies by Bijoy et al, Narwane et al, and Sarkar et al. ${ }^{13-15}$ This is different to the study done by Das et al, where female patients predominate. ${ }^{16}$ Disease distribution pattern in current study shows that most common diagnosis was Scabies $(9.51 \%)$, which dictates the importance of hygiene and health education to prevent this infestation. This finding is different from other studies done by Symvoulakis et al, Baur et al, and Rao et al, in which, noninfectious diseases were most common. ${ }^{17-19}$ Next common condition was Acne vulgaris (8.16\%). This finding is somewhat similar to study done by Sajith et al, and Anuj Kumar Pathak et al. ${ }^{20,21}$ A prescription is the reflection of prescriber's knowledge and attitude towards the disease management. In the current study, the average number of drugs per prescription was found to be 2.74 which is slightly higher than recommended by Narwane et al. ${ }^{14}$ The optimum value of mean number of drugs per prescription is $<2 .{ }^{22}$ It is preferable to keep the average number of drugs per prescription as low as possible since simultaneous use of multiple drugs may lead to increased risk of drug-drug interactions, adverse drug reactions, poor patient compliance and eventually increased cost of therapy. Present study results revealed that the percentage of drugs prescribed by the generic name was $79.26 \%$. The proposed optimal value of drugs prescribed by the generic name is $100 \% .^{22}$ Prescribing by brand name may be associated with several reasons such as faith of prescribers on branded products, extensive promotional activities of pharmaceutical companies influencing prescribers' decisions etc. Prescribing drugs by their generic names decreases the prescription errors, it's also known to increases accessibility and prescription compliance due to lower cost of generic products. ${ }^{23}$ Irrational prescription of antibiotics is a universal problem that ultimately leads to adverse drug reactions and frequent hospital admissions. ${ }^{24}$ The present study results showed that the antibiotics were 
prescribed in $18.68 \%$ of the total prescriptions. The proposed optimal range for an antibiotic prescribed is $<30 \%$. $^{22}$ In different countries percentage of prescription containing antibiotics was between $27 \%$ to $63 \% .{ }^{11}$ So, the antibiotics prescription percentage in present study was found as per the recommended guidelines.

In different countries percentage of prescriptions containing injections was between $0.2 \%$ to $48 \% .^{11}$ The present study revealed that the percentage of prescriptions with an injection prescribed was $3.26 \%$, whereas proposed optimal value for an injection prescribed is $<20 \%$. $^{22}$ This suggest that the prescription percentage of injections in present study was found as per the recommended guidelines, this could be due to studied unit i.e. dermatology where injections are minimally used. Percentage of drugs prescribed from state essential drugs list was $78.37 \%$ in present study.

Although the findings of this study are comparable to earlier studies, on comparing with the proposed optimum value i.e. $100 \%$, present result was found to be not complying the guidelines. This could be because of inadequate supply of the EDL drugs or inadequacy of essential drug list, so the review of state EDL is recommended. ${ }^{11,22}$

The results of current study showed that the average consultation time was 2.9. This is comparable with earlier studies where the average consultation time was found in range between 2.3-6.3 min but not complying with the proposed optimal time i.e. $\geq 10$ min. ${ }^{11}$ The shorter than optimal consultation time reported in this study could be the consequence of large number of patients per physician. Insufficient consultation time may lead to incomplete patient examination and subsequent irrational therapy. ${ }^{24}$ The present study reported an average dispensing time of 58 seconds (optimal value $\geq 90 \mathrm{~s}$ ), which may be related to higher patient load. $84.63 \%$ of the prescribed drugs were actually dispensed and with adequately labelled. Shorter dispensing time may reflect that insufficient information regarding drug regimen, dosage, precautions and adverse effects were described to the patients, which may lead to non-compliance to the therapy.

Result of present study showed that, the percentage of patient's knowledge of the correct dosage was 37\%, whereas optimal value was $100 \% .^{22}$ It was very low than the recommended. Earlier studies showed variable results ranging from $27-81 \% .{ }^{11}$ Limited drug related knowledge of the patients may be related with the lower consultation and dispensing time as well as poor understanding of the patients and may lead to the irrational and inappropriate use of drugs. Present study revealed that the percentage availability of the EDL copy was $100 \%$ which is as per the proposed norms (optimal value 100\%). ${ }^{22}$ However, the percentage of key drugs (for specific diseases) in the stock were $61.86 \%$ (optimal value $100 \%$ ). ${ }^{11}$ Limited availability of key drugs might be associated with budgetary restriction or poor drug stock management system.

\section{CONCLUSION}

The data from the present study could serve as a framework upon which further action plan can be generated by researchers and policymakers to improve the quality of health care practices. Although we found some rationality in prescribing habit in this study particularly regarding the use of antibiotics and injections but polypharmacy, inadequate consultation and dispensing time along with poor patient's knowledge are the area to be improved. Availability of essential drugs and key drugs in stock should be improved to achieve rational therapeutic goal. Based on these findings, it is recommended that there should be continuous medical education about rational prescribing especially regarding the promotion of generic prescribing and prescribing from the essential drug list. It is recommended to increase the number of physicians to improve the patients to physician ratio to achieve adequate consultation time, which allows the development of healthy relationship between patient and physician and achieve the desired therapeutic outcome.

\section{ACKNOWLEDGEMENTS}

Authors would like to thank Department of Skin and V.D, Late BRKM Govt. Medical College, Jagdalpur (CG), India.

\section{Funding: No funding sources Conflict of interest: None declared \\ Ethical approval: The study was approved by the Institutional Ethics Committee}

\section{REFERENCES}

1. Definition of Prescription. Available at: https://en.oxforddictionaries.com/definition/prescripti on. Accessed 21 March 2019.

2. Caplan, Jeremy. "Cause of Death: Sloppy Doctors". Time. Jan. 15, 2007. Available at: http://content.time.com/time/health/article/0,8599,15 78074,00.html. Accessed 21 March 2019.

3. Badyal D. Practical Manual of Pharmacology. $1^{\text {st }}$ ed. Jaypee Brothers Medical Publishers, New Delhi; 2008: 112.

4. Velo GP, Minuz P. Medication errors: prescribing faults and prescription errors. Br J Clin Pharmacol. 2009 Jun;67(6):624-628.

5. Folli HL, Poole RL, Benitz WE, Russo JC. Medication error prevention by clinical pharmacists in two children's hospitals. Pediatrics. 1987 May $1 ; 79(5): 718-22$.

6. Blum KV, Abel SR, Urbanski CJ, Pierce JM. Medication error prevention by pharmacists. Am J Hosp Pharm. 1988 Sep 1;45(9):1902-3.

7. Lesar TS, Briceland L, Stein DS. Factors related to errors in medication prescribing. JAMA. 1997 Jan 22;277(4):312-7.

8. Bates DW, Cullen DJ, Laird N, Petersen LA, Small $\mathrm{SD}$, Servi D, et al. Incidence of adverse drug events 
and potential adverse drug events: implications for prevention. JAMA. 1995 Jul 5;274(1):29-34.

9. American Society of Health-System Pharmacists. Suggested definitions and relationships among medication misadventures, medication errors, adverse drug events, and adverse drug reactions. Am J Health Syst Pharm. 1998 Jan 15;55(2):165-6.

10. Sweileh WM. Audit of prescribing practices of topical corticosteroids in outpatient dermatology clinics in north Palestine. Eastern Mediterr Health J. 2006;12(1/2):161-9.

11. World Health Organization. How to Investigate Drug Use in Health Facilities. Selected Drug Use Indicators. Geneva: WHO; 1993. Available at: http://apps.who.int/medicinedocs/en/d/Js2289e/. Accessed 21 March 2019.

12. C.G. Essential drug list $5^{\text {th }}$ edition June 2016. Department of Health and Family Welfare. Government of Chhattisgarh. India.

13. Bijoy KP, Vidyadhar RS, Palak P, Chintan SP, Atmaram PP. Drug prescribing and economic analysis for skin diseases in dermatology OPD of an Indian tertiary care teaching hospital: a periodic audit. Ind $\mathrm{J}$ Pharm Pract. 2012;5(1):28-33.

14. Narwane SP, Patel TC, Shetty YC, Chikhalkar SB. Drug utilization and cost analysis for common skin diseases in dermatology OPD of an Indian tertiary care hospital-A prescription survey. $\mathrm{Br} \mathrm{J}$ Pharm Res. 2011;1(1):9-18.

15. Sarkar C, Das B, Sripathi H. Drug prescribing pattern in dermatology in a teaching hospital in western Nepal. J Nepal Med Assoc. 2001;41:241-6.

16. Das S, Chatterjee T. Pattern of skin diseases in a peripheral hospital's skin OPD: A study of 2550 patients. Ind J Dermatol. 2007 Apr 1;52(2):93.

17. Symvoulakis EK, Krasagakis K, Komninos ID, Kastrinakis I, Lyronis I, Philalithis A, Tosca AD. Primary care and pattern of skin diseases in a
Mediterranean island. BMC Fam Pract. 2006 Dec;7(1):6.

18. Baur B, Sarkar J, Manna N, Bandyopadhyay L. The pattern of dermatological disorders among patients attending the skin OPD of a tertiary care hospital in Kolkata, Ind J Dent Med Sci. 2013;3(4):04-9.

19. Rao GS, Kumar SS, Sandhya S. Pattern of skin diseases in an Indian village. Indian $\mathrm{J}$ Med Sci, 2003;57(3):108-10.

20. Sajith M, Lokhande KD, Padma S, Pawar AP. Prevalance of various skin disorders and prescribing pattern of antihistamines in tertiary care hospital, Pune. Int J Pharm Sci Res. 2014;5(03):73-7.

21. Pathak AK, Kumar S, Kumar M, Mohan L, Dikshit H. Study of drug utilization pattern for skin diseases in dermatology OPD of an Indian tertiary care hospitalA prescription survey. J Clin Diagn Res: JCDR. 2016 Feb;10(2):FC01-5.

22. Guide to Drug Financing Mechanisms. 1998 WHO. Available https://apps.who.int/medicinedocs/en/d/Jh2928e/\#Jh2 928e. Accessed 21 March 2019.

23. Sheppard A. Generic Medicines: Essential contributors to the long-term health of society. Ims Health. 2010 Mar;16.

24. Akl OA, El Mahalli AA, Elkahky AA, Salem AM. WHO/INRUD drug use indicators at primary healthcare centers in Alexandria, Egypt. J Taibah Univ Med Sci. 2014;9(1):54-64.

Cite this article as: Jaiswal MK, Chakrawarty RK, Sharma SK, Sharma RK, Bharti RK, Agrawal R. A world health organization core drug use indicator based prescription study in the dermatology outpatient department of a tertiary care teaching hospital of central South India. Int J Basic Clin Pharmacol 2019;8:1896-901. 